\title{
Banana Fibre-Reinforcement of a Soil Stabilized with Sodium Silicate
}

\author{
Ravindran Gobinath ${ }^{1}$ - Isaac Ibukun Akinwumi ${ }^{2}$ (D) Olaniyi Diran Afolayan ${ }^{2} \cdot$ Saravana Karthikeyan $^{3}$. \\ Murugasamu Manojkumar $^{3} \cdot$ Sivaraj Gowtham $^{3} \cdot$ Ayyasamy Manikandan $^{3}$
}

Received: 14 December 2018 / Accepted: 4 March 2019

(C) Springer Nature B.V. 2019

\begin{abstract}
Many unsuitable soils for construction purposes can be made suitable by using unconventional soil stabilizers. This study investigates the effects of banana fibre-reinforcement of a soil stabilized with sodium silicate on the geotechnical properties of the composite. It involved the application of $1 \%$ sodium silicate with varying proportion $(0.1,0.2$, $0.3,0.4$ and $0.5 \%$ ) of banana fibre to a gravelly sand. Index properties, unconfined compression, direct shear, splittensile and California bearing ratio (CBR) tests were determined for the stabilized soil and the reinforced soil samples. The results show that the plasticity index, unconfined compressive strength (UCS), shear strength, splittensile strength and CBR of the specimens stabilized with sodium silicate increased with increasing percentage of banana fibre content. The application of $0.5 \%$ banana fibre strengthened the soil - the UCS increased by $445 \%$, shear strength by $80 \%$, split tensile strength by $194 \%$ and the soaked CBR increased by $1083 \%$. The banana fibrereinforcement of the sodium silicate stabilized sandy soils made the stabilized soil become suitable for road pavement application as sub-base material.
\end{abstract}

Keywords Foundation $\cdot$ Geotechnics $\cdot$ Materials $\cdot$ Soil improvement $\cdot$ Waste management

\section{Introduction}

Soils that would have been discarded some past decades ago because of their poor engineering properties, while selecting suitable materials for construction, have become soils that construction engineers can no longer ignore. This is because suitable soils for construction are getting depleted [1-3]. Stabilization of soils using additives has been a popular method of improving their engineering properties to make them suitable for use as construction materials. Some stabilizers that have been investigated in the past include: cement, lime, ecosand [4], precipitated silica [5], cactus mucilage [6], fly ash [7], waste marble fines [8], bottom ash [9], corncob ash [10], rice husk ash [11], steel slag [12], groundnut shell ash

Isaac Ibukun Akinwumi

isaac.akinwumi@covenantuniversity.edu.ng

1 SR Engineering College, Warangal, Telangana, India

2 Department of Civil Engineering, Covenant University, Ota, Ogun State, Nigeria

3 Jay Shriram Group of Institutions, Tirupur, Tamilnadu, India
[13], reclaimed asphalt pavement [14] and calcium carbide residue [15].

This research work investigates the suitability of using the combination of sodium silicate and banana fibres to stabilize a soil. Banana fibre, which is a natural fibre, is usually obtained from the waste produced from the banana plantation. Sodium silicate is a liquefied material obtained from heating sand with an excess amount of alkali, it is also obtained by blending sodium carbonate with silicon dioxide with the evolution of carbon dioxide gas. This former reaction produces a white powder of sodium silicate which then mixed with water to form an alkaline solution. This alkaline solution is then heated or melted to form a gelatinous fluid. Sodium silicate is also known as water glass or liquid glass for its appearance. Its use includes as adhesives, drilling fluids, concrete and masonry treatment, fire protection and refractory. Kazemian et al. [16] explored the combined use of cement and sodium silicate to stabilize an organic soil and found it suitable for strengthening the soil and reducing its moisture content. Vakili et al. [17] found that the inclusion of slag and sodium silicate significantly improved the strength of a cemented soil. Consequently, this study explores the use of sodium silicate and banana fibres for soil stabilization. 